\title{
Position Restructuring at Peking University Library
}

\author{
Zhuo-Xian Gao \\ Translated by Sha Li Zhang
}

\begin{abstract}
Peking University Library initiated position restructuring in response to the university's requirements and to the increasing demands and expectations of users. The goals were to reduce unwanted positions and at the same to enhance the responsibilities of selected positions. The restructuring promised to improve library services and staff morale. This article describes some steps taken in the position restructuring process at the Peking University Library that may help other academic libraries in China in a similar undertaking.
\end{abstract}

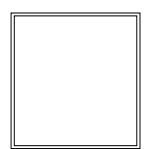

eking University, located in the northwestern part of Beijing, the People's Republic of China, is one of the most prestigious educational institutions in China. There are more than 13,000 undergraduate students, 9,000 graduate students, and 7,000 faculty and support staff at the university.

\section{The goals of the restructuring were to reduce the number of employees from 7,000 to 5,000 and at the same time to enhance the responsibilities of each position in all units in order to build strong academic programs and supporting functions.}

Of the university's 7,000 employees, 66 percent are administrative personnel, support staff (including the university library, media services, and the university computing center), and physical plant personnel; 34 percent are teaching and research faculty.
Like many government-supported institutions in China, for a long time, all the positions at Peking University have been permanent appointments. That is, after an individual was hired to take a position at the university, he or she would have lifelong employment with the institution, unless this individual voluntarily resigned from the job. Although the majority of individuals through such employment became productive members of the institution, some were less productive than others. In the old system, it was difficult for the university to replace this group of employees.

At the end of June 1999, the university began a campuswide restructuring of all positions. The goals of the restructuring were to reduce the number of employees from 7,000 to 5,000 and at the same time to enhance the responsibilities of each position in all units in order to build strong academic programs and supporting functions. Through the restructuring, the tra-

Zhuo-Xian Gao is a Library Director at Peking University Library; e-mail: gaozx@lib.pku.edu.cn. Sha Li Zhang is Head of Technical Services at Wichita State University Libraries; e-mail: zhang@twsuvm.uc.twsu.edu. The original version of this article appeared in China's Journal of Academic Libraries 18, no. 5 (2000): 63-66. 
ditional system of lifelong employment would be phased out. The chain of "Iron Rice Bowl" (the nickname for a secure job) would be eliminated. The environment in which competition was encouraged would be created, and talented individuals would find room to grow.

The university required each college, department, academic program, and support unit to provide head counts of active employees (excluding those who took long leaves) at the time of the restructuring. Based on those numbers, 85 percent of the positions were being reevaluated. Qualified employees within the university were later rehired. When the university started the position restructuring process, it also redistributed salaries and stipends. Each position kept the basic salary so that the employees were able to maintain their current living standards. Stipends would be added to each position according to its level of importance. If the position's duties changed, the stipends would change accordingly. In this way, employees with a high quality of performance would be rewarded financially.

\section{The University Library}

The Peking University Library is one of the supporting units for teaching and research at the university. The library holds more than four million volumes. Its operational units include acquisitions, administrative office, automation, cataloging, circulation and reading, information and reference, media, rare books and special collections, and serials and reading.
In 1998, a new library addition was completed. In conjunction with celebrating the completion of the new library and the centennial of the university, the library hosted an international conference on New Missions of Academic Libraries in the Twenty-first Century, in October 1998. The new library is the expansion of the existing one, which brings the total space to 550,000 square feet. The open shelves increased from 300,000 volumes to a million volumes. The total number of seats increased from 1,700 to 4,000. Daily visits to the library have reached 20,000 . Six service points at the library operate from 8:00 a.m. to 10:00 p.m. The Information and Reference Department offers one-hour series on using the library on a regular basis. Both students and faculty welcomed the improved library services.

In the past decade, the library continued reducing the total number of positions, from 261 in 1989 to 202 in 2000 (see table 1). Taking the total number of staff in 2000, for example, among 202 employees, 82.7 percent are professional positions. The percentage of professional librarians at the Peking University Library is higher than that in developed countries such as the United States and Japan. According to higher education statistics published in early 1990s, among all fifty states in the United States, the total number of library employees in college and university libraries was 96,244 . Of that number, 26,000 were professional librarians (27\%), 40,000 were support staff (42\%),

\begin{tabular}{|cccccc|}
\hline \multicolumn{7}{c|}{ TABLE 1 } \\
Year & $\begin{array}{c}\text { Total } \\
\text { Number } \\
\text { of Staff }\end{array}$ & $\begin{array}{c}\text { Senior } \\
\text { Rank Staff \% }\end{array}$ & $\begin{array}{c}\text { Middle } \\
\text { Rank Staff \% }\end{array}$ & $\begin{array}{c}\text { Junior } \\
\text { Rank Staff \% }\end{array}$ & Clerks \% \\
\hline \hline 1989 & 261 & 12.3 & 31.4 & 33.4 & 22.9 \\
1994 & 237 & 18.9 & 29.1 & 26.1 & 25.9 \\
1997 & 214 & 21 & 30 & 27 & 22 \\
1999 & 210 & 21.7 & 37.1 & 24.1 & 17.1 \\
2000 & 202 & 21.8 & 37.6 & 23.3 & 17.3 \\
\hline
\end{tabular}


29,000 were student workers (30\%), and 400 were library volunteers. ${ }^{1}$ In Japan, the number of professional librarians should not exceed 56 percent. It is believed that library functions such as user services and academic department liaisons should be the responsibilities of professional librarians. However, other functions, such as materials processing, general user directional services, and other quantified library management, should be performed by support staff.

At the Peking University Library, staff members were traditionally assigned to library positions by the university with little input from the library. Some of those who were assigned to the library positions did not like their jobs. Furthermore, some did not fit or qualify for the positions. As a result, there were more positions and more staff in the library than it actually needed, yet productivity was still low. With the opening of the new library in 1998, the increased workload and user expectations demanded better library services. This, in turn, provided the library with the opportunity to address issues on positions, the recruitment process, and a reward system. After several long discussions and debates, the library decided to take the opportunity to restructure all positions.

\section{The Library Position Restructuring}

At the request of the university, the library submitted two documents in June 1999: "Position Goals and Responsibilities" and "Key Position Redesign and Personnel Recruitment," including redistributing personnel within the university, position redesigns, recruitment, a reward system, and procedures of appointments. These documents clearly stated the library's service objectives for the next three years, which were to:

- provide networked resources;

- develop needed collections;

- enhance interlibrary loans and document delivery;

- improve processing efficiency; and

- create a user-friendly library environment. $^{2}$
Obviously, realizing these objectives requires human capital. Restructuring positions would be an important step toward maximizing such capital. The library reopened all positions and conducted recruitment internally. After one year of implementation, all the positions were filled. Appropriate salary and stipends were allocated to each position according to its level of responsibilities. This initiative provided a solid foundation for continuous assessment of all positions in the library. The university recognized the library's recommendations by allocating appropriate stipends to the library.

Overall, this initiative reached the goals defined in the guidelines proposed by the library. It helped improve the quality of library services, efficiency, and staff morale. The salary and the stipend for each position are based on the position's level of responsibilities. The individuals who were in key positions were given a higher rank of salary and stipends than those who were not. The total number of positions was reduced, but the quality of each position was improved. The following steps taken at the Peking University Library may provide some insight for other academic libraries in China:

1. At the beginning, the Position Assessment Committee was formed in the library to carry out the restructuring task. The committee included senior library administrators, middle managers, and librarian and staff representatives, and was responsible for facilitating communications on position restructuring issues between the university and library staff.

2 . The two library documents submitted to the university were made available to the entire staff of the library. The number of positions and the qualifications for these positions also were announced. This gave the library staff the opportunity to comment on the positions and to become familiar with the process. Staff members were encouraged to choose the positions that were suitable to their qualifications and offered them potential.

3. Each staff member was asked to write a self-evaluation for the past three 
years (no fewer than 1,500 words), including accomplishments, credentials, performance, and areas that needed improvement. Each staff member also was requested to set goals for the next three years. Most of the staff selected appropriate positions. The department heads and program coordinators endorsed the evaluations and made recommendations to the library based on the evaluations provided.

\section{Whereas 85 percent of the positions were rewarded with stipends after the restructuring, about 15 percent of the library staff did not get position stipends due to long-term absences and poor performance.}

4. The committee reviewed the initial recommendations made by department heads based on the guidelines. Then, it produced a list of appointees to include in the first group to be announced.

5. The committee took this list to the staff for additional comments. Suggestion boxes were provided for input. Each staff member was asked to identify him- or herself when the committee reviewed each appointee. Anonymous evaluations were considered invalid.

6. With input from the entire staff in the library, the committee voted for the final recommendations of appointees and this list was submitted to the university for approval.

7. Upon the university's approval, the library and the appointees signed official employment contracts at the library.

The library's Position Assessment Committee predicted that the total number of positions needed would be 184, but the university had planned for only 177 (see table 2). Therefore, the library had to follow the university's guidelines to keep the number of positions within that limit. The committee carefully reviewed each position's title, responsibilities, qualifications, and rank. The job description for each position was clearly defined and precisely described to avoid any misunderstanding, with room for maintaining flexibility and coordination among positions.

The library's position restructuring, recruitment, and competition for the respective position were accompanied with the changes in position stipends. A person who left the position would keep only the basic salary; the stipend would stay with the position. If the responsibilities of the position were to change, the stipends also would change. In some cases, staff with the senior librarian rank would not necessarily be appointed to a position with a high stipend, and vice versa.

The university issued campuswide position ranks from one (the highest position) to nine (the lowest position), as shown in table 2 . The library adopted the ranks and integrated them into its operational functions. The level of rank depended on the following factors:

- the services provided, including reference and instruction, circulation, materials acquisitions, cataloging and processing, automation, support system, operational administration, and maintenance;

- the quantity of services, for instance, the volume of materials cataloged and processed, the number of library us-

\begin{tabular}{|lcc|}
\hline \multicolumn{3}{|c|}{ TABLE 2 } \\
\hline \multicolumn{2}{|c|}{ Number of Positions after Restructuring } \\
\hline Positions & $\begin{array}{c}\text { Predicted Number } \\
\text { of Appointments }\end{array}$ & $\begin{array}{c}\text { Actual } \\
\text { Appointments }\end{array}$ \\
\hline 1 & 0 & 0 \\
2 & 3 & 1 \\
3 & 5 & 5 \\
4 & 12 & 14 \\
5 & 22 & 19 \\
6 & 40 & 36 \\
7 & 49 & 51 \\
8 & 36 & 34 \\
9 & 17 & 17 \\
\hline Total & $\mathbf{1 8 4}$ & $\mathbf{1 7 7}$ \\
\hline
\end{tabular}


ers served, the space of reading rooms and shelves in the service areas, the number of reference questions answered, and the number of materials circulated;

- the actual job descriptions and required credentials; and

- qualifications, such as job performance, experience, and working attitude.

The library's position restructuring had a significant impact on traditional lifelong employment. Two groups of people were substantially affected during the restructuring: those whose performance and qualifications did not meet the requirements of the position, and those whose positions were eliminated and who needed another position within the university. The university's position transfer and recruitment policy covered these two groups. When the library expanded hours and services that needed more staff, the university provided support so that the library could recruit staff from other units on campus. At the same time, the library could transfer those who did not fit the library job to another unit of the university. Whereas 85 percent of the positions were rewarded with stipends after the restructuring, about 15 percent of the library staff did not get position stipends due to long-term absences and poor performance.

During the initial restructuring, the library was unable to open its positions to the entire university community because some staff would be unable to find employment elsewhere due to historical lifelong employment. These staff members were unprepared for competition outside the library. However, in general, reappointment within the library reached the goals of reducing the total number of positions and enhancing each position by placing the right person in the right position.

Another issue that needed to be considered during the restructuring was the relation between each staff member's academic rank and the level of the position. There are several ranks among the library staff, such as senior rank (full librarian), middle rank (associate librarian), junior rank (assistant librarian), and clerk. In the past, as soon as some staff members had obtained a certain rank, they became less productive, which had a negative impact on staff morale. The library restructured the positions based on need, not on rank. Therefore, when the library reopened all the positions, some high-rank staff could not be given positions with high stipends because of past performance and a poor work attitude. Some younger staff members with proven performance and potential in the Automation Department, Information and Reference Department, and Cataloging Department were assigned to positions with high stipends. This type of change in the personnel structure helped improve library services and provided direction for future personnel management.

\section{Useful Tips}

In the first year of implementation, the majority of library staff and those elsewhere in the university looked positively at the campuswide position restructuring. This initiative attracted talented people to each position and provided a solid foundation for future restructuring in salary and personnel. Library records documenting the first year of implementation reflected improvements in services, operations, management, and staff benefits. The users' satisfaction level also improved. To continue the position restructuring, the library administration noted that several key issues deserve special attention, including:

1. The librarywide position restructuring depended heavily on the involvement of department heads and program coordinators. Their understanding and motivation directly affected the outcome of the restructuring process. The library held several meetings and discussions with the department heads and coordinators who assisted in designing new positions, writing job descriptions, composing qualifications for each position, and predicting stipend differences for all positions. The Position Assessment Committee carefully reviewed proposals submit- 
ted by the department heads and coordinators, provided constructive suggestions and advice, and approved the final recommendations. During this process, department heads and coordinators displayed support, capability, and enthusiasm for the position restructuring.

2. The success of the position restructuring depended on the entire staff's understanding and attitudes. Through department heads and program coordinators, the staff had opportunities to provide input on position recommendations and voice their concerns. Therefore, they were convinced that the restructuring would result in improved library services.

3. A grieving process should be provided during the restructuring. The university had grieving procedures in place. The library staff could request such a process through the university's human resources and administrative offices. In addition, the Position Assessment Committee members listened to complaints and brought them to the full committee for discussion. This helped maintain position restructuring in an open, fair, and democratic process.

The library paid special attention to staff input on position appointment. The committee discussed some appointments three or four times. In general, feedback from the staff was positive. Some did not like their new appointments at first, but after the grieving process, in which they discussed their concerns, they were able to accept the change.

4. The bonuses provided by the library came from its external incomes and supplemented the position stipends. After the position restructuring process, some staff members were appointed to positions with low stipends, which caused some resentment. However, because the library drew the supplements from its external incomes, the staff felt that the library was on their side and cared about them.

\section{Conclusion}

The first year of implementation proved to be successful. The library director, on behalf of the entire staff, submitted a three-year plan to the university promising that it would meet the goal of building the world-class library the university had requested. To reach that goal, the library would devote its energy and resources in collections, staff training and development, high-quality services, modern library management, and use of advanced technology. The library will continue to strive for excellence to meet the increasing demands of its users.

\section{Notes}

1. "University and College Libraries," in ALA World Encyclopedia of Library and Information Services (Chicago: ALA, 1993).

2. "Position Goals and Responsibilities" and "Key Position Redesign and Personnel Recruitment," Peking University Library, June 1999. (Unpublished documents) 